\title{
Analysis of Medical Seeking Behavior and Influencing Factors in Patients With Chronic Obstructive Pulmonary Disease
}

\section{Zhongshang Dai}

Second Xiangya Hospital of Central South University

\section{Yiming Ma}

Second Xiangya Hospital of Central South University

\section{Zijie Zhan}

Second Xiangya Hospital of Central South University

Yan Chen ( $\nabla$ chenyan99727@csu.edu.cn )

Second Xiangya Hospital of Central South University

\section{Ping Chen}

Second Xiangya Hospital of Central South University

\section{Research Article}

Keywords: COPD, IQR, mMRC, medical

Posted Date: February 3rd, 2021

DOl: https://doi.org/10.21203/rs.3.rs-149811/v1

License: (c) (1) This work is licensed under a Creative Commons Attribution 4.0 International License. Read Full License

Version of Record: A version of this preprint was published at Scientific Reports on July 9th, 2021. See the published version at https://doi.org/10.1038/s41598-021-93499-9. 


\section{Abstract}

Purpose: To explore the status of medical seeking behavior in patients with chronic obstructive pulmonary disease (COPD), and clarify relevant factors that may affect the diagnosis delay.

Methods: A cross-sectional study was conducted in a Chinese tertiary hospital from July 2019 to February 2020. A total of 408 eligible outpatient COPD patients were recruited and relevant data were collected in the form of questionnaire. Diagnosis delay was compared among different characteristics using Wilcoxon test and Kruskal-Wallis $\mathrm{H}$ test. Correlation analysis were performed to further explore factors related to diagnosis delay.

Results: The median (interquartile range [IQR]) duration of diagnosis delay was 230 (50 - 720) days. Proportions of COPD patients who chose tertiary hospitals, secondary hospitals, and first - level hospitals for the first visit were respectively $53.7 \%, 29.9 \%$ and $16.4 \%$. Additionally, proportions of patients who received pulmonary function test for the first visit in tertiary hospitals, secondary hospitals, and first - level hospitals were namely, $83.9 \%, 15.5 \%$, and $1.5 \%$ ( $p<0.001)$. In terms of characteristics related to diagnosis delay, there is a significant difference in residence, resident manner, CAT , mMRC, age, FEV1\% predicted, years of education, average family income $(p<0.001)$. Furthermore, diagnosis delay is correlated with patients' knowledge level of COPD and other characteristic variables (including age, years of education, resident manner, average family income, CAT , mMRC, FEV1\% predicted, and FEV1/FVC) to varying degrees.

Conclusion: Our study indicates that varying degrees of diagnosis delay may exist in COPD patients. Measures are needed to intervene potential factors related to diagnosis delay.

\section{Introduction}

Chronic obstructive pulmonary disease (COPD) has become a global public health challenge due to its high prevalence and related mortality. ${ }^{1}$

The 2013 Global Burden of Disease (GBD 2013) report pointed out that COPD is the third leading cause of death in the world, with approximately 3 million people dying from COPD each year. ${ }^{2}$ In China, the results of a latest national survey in 2018 showed that there are close to 100 million COPD patients, and the prevalence rate of people over 40 years old is $13.7 \% .{ }^{3}$ Consequently, early diagnosis and intervention of COPD are of great value for preventing the progression of the disease. ${ }^{4}$ Several studies have demonstrated that early intervention in patients with COPD may improve lung function. ${ }^{5-7}$ The results of the UPLIFT study showed that early intervention can reduce the number of acute exacerbations of COPD. However, many factors such as physician-related factors, patient-related factors and the heterogeneity of the disease itself may have an impact on the early diagnosis of COPD. ${ }^{8}$ COPD patients generally have insufficient knowledge of the disease and low awareness rate, ${ }^{9}$ which may work together with other factors to cause delays in the diagnosis and intervention of COPD. China Pulmonary Health (CPH) study 
showed that only $2.6 \%$ of patients diagnosed with COPD by pulmonary function test knew they had COPD. ${ }^{3} \mathrm{~A}$ study from South Korea indicated that among male smokers, only $23.8 \%$ were aware of COPD and $30.5 \%$ had undergone lung function tests. ${ }^{10}$ Another study from Denmark showed that $28 \%$ of smokers did not consider COPD to be a fatal disease. ${ }^{11}$

Medical seeking behavior refers to the whole process from perceiving symptoms to seeking medical care for the purpose of prevention or early detection of disease and treatment. ${ }^{12}$ Proper medical seeking behavior is one of the important measures to reduce illness and early treatment, and is also a key issue related to disease transmission and disease control. Diagnosis delay refers to the time interval between the onset of symptoms and the date of diagnosis. ${ }^{13}$ It is one of the most important indicators for evaluating medical seeking behavior. Medical seeking behavior has been well studied in infectious diseases (malaria, sexually transmitted diseases, tuberculosis) and psychiatric diseases, as well as in chronic diseases such as diabetes and hypertension. Wang's study found that the less tuberculosis knowledge was known, the more likely it was to delay a visit to medical institutions. Patients aged 15-44 years were most likely to have delayed visits. ${ }^{14}$ People with uninsured suspicious symptoms without medical insurance tend to have longer delays in seeing a doctor. A study in India suggested that people's awareness of diabetes and residence might influence their medical seeking behavior. ${ }^{15}$

However, there have been no studies on medical seeking behavior and influencing factors of COPD patients at home and abroad. There is a large population of COPD patients in China, so we are committed to a comprehensive analysis to investigate medical seeking behavior of COPD patients and explore factors that may relate to the diagnosis delay, which may be of certain value to realize the early diagnosis and intervention of COPD.

\section{Methods}

\section{Study design}

This was a real-world, cross-sectional study of outpatients with COPD in a large Chinese tertiary teaching hospital. The study obtained ethical approval from the ethics committee of the Second Xiangya Hospital, Central South University. (number: ChiCTR-POC-17010431.) We got informed consent from all study participants. All methods were carried out in accordance with COPD guidelines and regulations. ${ }^{9}$

\section{Study patients and procedures}

The patients were included if they had been diagnosed with COPD according to GOLD 2019 criteria and the age ranged from 35 to 80 years old. All patients visited the respiratory outpatient department of the Second Xiangya Hospital from July 2019 to February 2020 and were in stable condition. The exclusion criteria were those who were unable to complete the questionnaire, had severe heart, brain, liver, kidney and hematopoietic diseases other than respiratory diseases, and obvious cognitive dysfunction. 
We performed the study in the form of questionnaires, including self-made questionnaire, COPD Assessment Test (CAT) questionnaire, modified Medical British Research Council (mMRC) dyspnea scale and COPD knowledge questionnaire (COPD-Q) involved in the literature. ${ }^{16}$ Face-to-face interviews were conducted among the included patients by specially-assigned persons. The self-made questionnaire included the sex, age, number of exacerbations in the previous year, number of hospitalizations in the previous year, smoking pack-years, forced expiratory volume in one second (FEV1)\% predicted, FEV1/forced vital capacity (FVC), residence, the resident manner, years of education, average family income, medical insurance, diagnosis delay, hospital classification for first visit, and previous history receiving pulmonary function test.

\section{Data Analysis}

The data were analyzed using Statistical Package for Social Sciences (SPSS) version 21.0 and R software version 3.6.2 (R Foundation for Statistical Computing). Descriptive data without normal distribution were expressed as medians (interquartile range [IQR]) and frequencies were expressed as number (percentage). The Wilcoxon test and the Kruskal-Wallis $\mathrm{H}$ test were utilized to compare the diagnosis delay classified by outpatients' demographic variables. Correlation analysis were performed to further explore factors related to diagnosis delay. A p-value of less than 0.05 was considered significant.

\section{Results}

\section{Demographic Characteristics}

From the original queue including 530 outpatients in the respiratory department of the Second Xiangya Hospital from July 2019 to February 2020, 122 patients were excluded in which 12 patients were unable to read questionnaire, 25 patients had no spirometry results, 13 patients did not meet the COPD diagnostic criteria, 11 patients presented with COPD as secondary diagnosis , 21 patients had no mMRC/CAT score, 40 patients had no data of diagnosis delay. Finally, a total of 408 outpatients meeting study criteria were included (Figure 1).

Table 1 depicts the outpatients' demographic characteristics. Males constituted $90.2 \%$ of the respondent group, while $9.8 \%$ were female. The majority $(66.4 \%)$ of the participants were not first-time diagnosed COPD patients. $41.5 \%$ of patients had no acute exacerbation, $27.3 \%$ had an acute exacerbation and $31.2 \%$ had 2 or more acute exacerbations in the previous year. Nearly two-thirds of the participants lived in rural areas, and $33.1 \%$ lived in cities. The vast majority (92.2\%) of patients did not live alone, yet $7.8 \%$ lived alone. Almost all patients (97.8\%) had medical insurance in this study, while $2.2 \%$ did not. $16.4 \%$ of the respondents chose first-level hospitals for their first visit, $29.9 \%$ chose secondary hospitals and $53.7 \%$ chose tertiary hospitals for their first visit. Almost half (47.3\%) of the patients received pulmonary function test in their first visit, while $52.7 \%$ did not. The median (IQR) of age, hospitalizations in the previous year, smoking pack-years, FEV1\% predicted, FEV1/FVC, CAT, mMRC, COPD-Q, years of education, 
average family income and diagnosis delay were 65 (58 - 69), 0 (0 - 1), 40 (20 - 58), 53.3 (35.2 - 69.2), 47(36.4 - 58.9), 13 (8 - 18), 2 (1 - 3), 4 (0 - 6), 9 (6 - 9), 1 (0.5 - 2), and 230 (50 - 720).

The proportion of COPD outpatients who chose tertiary hospitals for the first visit was greater than that of secondary hospitals or first-level hospitals (Figure 2). Furthermore, with the increase of hospital level, the proportion of patients undergoing pulmonary function test in the first visit gradually increased $(p<0.001)$ (Table 2).

\section{Analysis of Diagnosis Delay and characteristic variables}

Tables 3 and 4 report the findings of the Wilcoxon test and the Kruskal-Wallis $\mathrm{H}$ analysis, which were performed to explore differences of diagnosis delay among different characteristics. In terms of diagnosis delay, there was a significant difference in rural area and city, living alone and not living alone, CAT $<10$ and CAT $\geq 10$, mMRC $<2$ and $m M R C \geq 2(p<0.001)$. The rural area, living alone, CAT $\geq 10$ and mMRC $\geq 2$ showed a higher median than city, not living alone, CAT $<10$ and $m M R C<2$ (300 and 100, 660 and 200, 300 and 110,300 and 95, respectively). There was also a significant difference between the participants based on their age, FEV1\% predicted, years of education and average family income $(p<$ 0.001 ); older outpatients ( $\geq 70$ years), lower value of FEV1\% predicted ( $<30 \%)$, lower years of education ( $\leq 6$ years ) and lower average family incomes ( $<0.5$ Ten thousand RMB) showed a higher median than the participants in other corresponding groups.

Figure 3 shows that the diagnosis delay is negatively correlated with COPD-Q through correlation analysis, and the correlation coefficient value was -0.34 . Furthermore, figure 4 depicts the correlation coefficients among all characteristic variables. Except for sex, residence, first pulmonary function test and first diagnosis, diagnosis delay is positively correlated with age, the resident manner, mMRC and CAT, with correlation coefficients of $0.14,0.24,0.16$, and 0.16 , respectively. On the contrary, diagnosis delay is negatively correlated with years of education, average family income, FEV1\% predicted and FEV1/FVC, and the correlation coefficients are $-0.18,-0.28,-0.21,-0.2$, respectively.

\section{Discussion}

As far as we know, this is the first study investigating medical seeking behavior in COPD patients. The COPD-Q questionnaire can be used as a simple criterion to reflect the patient's knowledge and cognition of COPD and in our study, the median score for COPD-Q was 4 points (maximal of 13 points), which is consistent with the literature. ${ }^{17}$ The diagnosis delay is one of the most important indicators of medical seeking behavior, which can be divided into factors related to health care providers, patient-related factors, and the heterogeneity of the disease itself and we also found out that COPD patients had varying degrees of diagnosis delay (median [IQR]: 230 [50-720] days). Another study about delayed diagnosis of alpha-1 antitrypsin deficiency got similar results; ${ }^{18}$ in addition, their research showed that the relationship between the diagnosis delay and all prognosis was consistent with an adverse effect of increasing diagnosis delay. For every additional year of delay in diagnosis, the subject's FEV1\% predicted decreased. 
In a recent retrospective study, Debra $T$ Choi made a conclusion that nearly half of patients with liver cirrhosis delayed the diagnosis of HCC within 60 days or more after the danger signs by using a multivariate logistic regression model. ${ }^{19} \mathrm{~A}$ new study from the United Kingdom on inflammatory bowel disease (IBD) has found the median diagnosis delay sub-intervals were: patients presentation $=2.1$ months; the doctor referral $=0.3$ months; secondary care diagnosis $=1.1$ months. $92 \%$ of patients were diagnosed within 2 years of symptoms and $50 \%$ were diagnosed within 4 months. ${ }^{20}$ Compared with other studies, the diagnosis delay in COPD patients was longer; it may result from that COPD was a chronic disease with a longer disease process and gradual aggravation of symptoms, while patients with other digestive diseases such as IBD often had diarrhea and blood in the stool as the first symptoms, so they were more likely to catch symptoms early, and these symptoms were more difficult to tolerate.

In this study, we found that half of patients were first diagnosed in tertiary hospitals due to COPD, while the proportion was much lower than that of first - level and secondary hospitals. A newer study from South Korea enrolled a total of 645,031 patients of tuberculous destroyed lung over five years. During the study period, $98.5 \%$ of patients went to primary hospitals, $71.1 \%$ and $93.2 \%$ to secondary and tertiary hospitals, respectively. ${ }^{21}$ There was no significant difference in the proportion of visits to the three different levels of hospitals in the study, but there was no record of first-time visits. Consistent with the results we expect, the proportion of patients whose first diagnosis institution was a high-level hospital undergoing pulmonary function tests was much higher than that of primary hospitals. Many studies have shown that among COPD patients, the proportion of patients who have undergone pulmonary function tests is not high. ${ }^{10,22,23}$ However, these studies did not analyze the classification of the hospital where the patient visited. In fact, the proportion of COPD patients who went to tertiary hospitals for the first diagnosis receiving lung function was not low (83.9\%) in our study, and it was higher than reported in the literature. $3,22,23$ Therefore, the classification of hospitals is more conducive to understanding the true status of patients' lung function. In addition, this also illustrates the importance of propagating and popularizing lung function tests to primary hospitals.

We also observed that the diagnosis delay for outpatients living in rural areas was significantly higher than that in cities. Several recent studies $24,25,26,27$ around the world revealed the greatest decrease in the analyzed measures of the standard expected years of life lost due to COPD was observed among males from rural areas in Poland $(p<0.05)$ (SEYLL: AAPC $=-1.6$ ) and COPD patients living in rural areas of Mexico were more likely to be Biomass smoke exposure (47\%) and had a higher prevalence. Besides that multivariate logistic regression indicated that lower educational levels and poor access to medical services was associated with an overall higher risk of COPD as well as a lower probability of COPD ( $P=$ 0.002) in rural Southwest China. Based on the analysis of various factors, it can be understood why the diagnosis delay in rural areas is higher than that in cities. Few studies have explored the relationship between diagnosis delay of COPD patients and the resident manner囚but there are significant differences in our study. The results of a foreign study implied that elderly men living alone have an increased risk of depressive symptoms directly or indirectly by reducing their sense of belonging. ${ }^{28}$ While, another study aimed at determining whether there is a link between living alone and suffering from malnutrition in a 
Mediterranean population concluded that living alone was not associated with states of malnutrition or having the risk of suffer from it. ${ }^{29}$ We speculated that patients living alone may be due to lack of supervision from family members or financial constraints, or emotional depression and lack of selfseeking behavior, which increases the delay in medical treatment. An interesting finding is that the higher the symptom scores (CAT and mMRC) of COPD patients, the longer their visits will be delayed, which is different from our original assumptions. We thought that it might be because when the patient was in the early stage of the disease, the symptoms were mild and had no significant impact on daily life, so he did not see a doctor in time. When the symptoms are severe enough to require medical attention, the delay will naturally increase.

Many studies have shown that the higher the education and the income level of patients, the higher the importance and compliance with the disease, the higher the degree of cooperation in daily medical work, and the better the disease control. ${ }^{30,31,32,33,34}$ Our research results also fully reflected this. With the increase in education years and income levels, the diagnosis delay of patients continued to decrease. Age is an independent risk factor for many diseases and we found that the diagnosis delay increased with age; however, patients in the 60-70 age group had a lower delay in seeking treatment, which we considered might be due to the high morbidity rate of patients in this age group, increased attention to their own health and increased family attention to their disease. In addition, as we predicted, the worse the patient's lung function was in our study, the longer the diagnostic delay was. Vickram Tejwani's study also concluded that for each additional year of diagnostic delay, the subject's $\mathrm{FEV}_{1} \%$ predicted decreased by $0.3 \%(P=0.004) .{ }^{18}$

Our study found that the diagnosis delay was negatively correlated with the COPD-Q score through correlation analysis, suggesting that the lower the COPD patients' awareness of the disease, the longer the delay in visits and the greater the delay in the condition. This suggests that we can strengthen the publicity and science popularization of COPD knowledge, so that everyone can understand COPD more clearly like hypertension and diabetes; when ordinary people know the severity and harm of COPD, early symptoms will be timely to see the doctor without delay. Not only the COPD-Q questionnaire, diagnosis delay is also correlated with many characteristic variables. This shows that diagnosis delay is a nonnegligible indicator for judging the condition of COPD patients. It also suggests that we can take some measures to improve the diagnosis delay of patients. to achieve the effect of improving the condition.

Although this cross-sectional study is the first to explore the medical seeking behavior and influencing factors in patients with COPD, it does have some limitations. First, since this study was restricted to outpatients from a single public hospital, the results should be generalized with caution. However, we believe our findings have important clinical implications. So future studies should examine other public and private hospitals to more broadly explore the medical seeking behavior and influencing factors in patients with COPD. Second, the diagnosis delay and the COPD-Q questionnaire in this study are too subjective, and patients may forget or remember incorrectly in a short time. Third, future studies should focus on other factors that might impact the level of diagnosis delay of COPD. 


\section{Conclusions}

In conclusion, our research confirms that varying degrees of diagnosis delay may exist in COPD patients. Secondly, the proportion of patients who choose tertiary hospitals for their first diagnosis and first lung function is higher than that of primary hospitals. Additionally, in terms of diagnosis delay, there is a significant difference in residence, the resident manner, CAT , mMRC, age, FEV1\% predicted, years of education, average family income. Moreover, correlation analysis suggests that diagnosis delay is correlated with COPD-Q and other characteristic variables to varying degrees. Measures are needed to intervene potential factors related to diagnosis delay.

\section{References}

1. López-Campos JL, Tan W, Soriano JB. Global burden of COPD. Respirology. 2016;21(1):14-23. doi:10.1111/resp.12660

2. GBD 2013 Mortality and Causes of Death Collaborators. Global, regional, and national age-sex specific all-cause and cause-specific mortality for 240 causes of death, 1990-2013: a systematic analysis for the Global Burden of Disease Study 2013. Lancet. 2015;385(9963):117-171. doi:10.1016/S0140-6736(14)61682-2

3. Wang $\mathrm{C}$, Xu J, Yang L, et al. Prevalence and risk factors of chronic obstructive pulmonary disease in China (the China Pulmonary Health [CPH] study): a national cross-sectional study. Lancet. 2018;391(10131):1706-1717. doi:10.1016/S0140-6736(18)30841-9

4. Welte T, Vogelmeier C, Papi A. COPD: early diagnosis and treatment to slow disease progression. Int J Clin Pract. 2015;69(3):336-349. doi:10.1111/ijcp.12522

5. Decramer M, Celli B, Kesten S, et al. Effect of tiotropium on outcomes in patients with moderate chronic obstructive pulmonary disease (UPLIFT): a prespecified subgroup analysis of a randomised controlled trial. Lancet. 2009;374(9696):1171-1178. doi:10.1016/S0140-6736(09)61298-8

6. Zhou Y, Zhong NS, Li X, et al. Tiotropium in Early-Stage Chronic Obstructive Pulmonary Disease. N Engl J Med. 2017;377(10):923-935. doi:10.1056/NEJMoa1700228

7. Jenkins CR, Jones PW, Calverley PM, et al. Efficacy of salmeterol/fluticasone propionate by GOLD stage of chronic obstructive pulmonary disease: analysis from the randomised, placebo-controlled TORCH study. Respir Res. 2009;10(1):59. Published 2009 Jun 30. doi:10.1186/1465-9921-10-59

8. Jagana R, Bartter T, Joshi M. Delay in diagnosis of chronic obstructive pulmonary disease: reasons and solutions. Curr Opin Pulm Med. 2015;21(2):121-126. doi:10.1097/MCP.0000000000000133

9. Singh D, Agusti A, Anzueto A, et al. Global Strategy for the Diagnosis, Management, and Prevention of Chronic Obstructive Lung Disease: the GOLD science committee report 2019. Eur Respir J. 2019;53(5):1900164. Published 2019 May 18. doi:10.1183/13993003.00164-2019

10. Hwang Yl, Park YB, Yoon HK, et al. Male current smokers have low awareness and optimistic bias about COPD: field survey results about COPD in Korea. Int J Chron Obstruct Pulmon Dis. 2019;14:271-277. Published 2019 Jan 21. doi:10.2147/COPD.S189859 
11. Sikjær MG, Hilberg O, Fløe A, Dollerup J, Løkke A. Lack of awareness towards smoking-related health risks, symptoms related to COPD, and attitudinal factors concerning smoking: an Internet-based survey conducted in a random sample of the Danish general population. Eur Clin Respir J. 2018;5(1):1506235. Published 2018 Aug 14. doi:10.1080/20018525.2018.1506235

12. Behavior medicine. Changsha: Hunan Science and Technology Press, 1999:470-493

13. Larsson K, Janson C, Ställberg B, et al. Impact of COPD diagnosis timing on clinical and economic outcomes: the ARCTIC observational cohort study. Int J Chron Obstruct Pulmon Dis. 2019;14:9951008. Published 2019 May 13. doi:10.2147/COPD.S195382

14. Wang Y, Long Q, Liu Q, Tolhurst R, Tang S. Treatment seeking for symptoms suggestive of TB: comparison between migrants and permanent urban residents in Chongqing, China. Trop Med Int Health. 2008;13(7):927-933. doi:10.1111/j.1365-3156.2008.02093.x

15. Kishore J, Kohli C, Gupta N, Kumar N, Sharma PK. Awareness, Practices and Treatment Seeking Behavior of Type 2 Diabetes Mellitus Patients in Delhi. Ann Med Health Sci Res. 2015;5(4):266-273. doi:10.4103/2141-9248.160184

16. Maples P, Franks A, Ray S, Stevens AB, Wallace LS. Development and validation of a low-literacy Chronic Obstructive Pulmonary Disease knowledge Questionnaire (COPD-Q). Patient Educ Couns. 2010;81(1):19-22. doi:10.1016/j.pec.2009.11.020

17. Yang $H$, Wang $H$, Du L, Wang $Y$, Wang $X$, Zhang R. Disease knowledge and self-management behavior of COPD patients in China. Medicine (Baltimore). 2019;98(8):e14460. doi:10.1097/MD.0000000000014460

18. Tejwani V, Nowacki AS, Fye E, Sanders C, Stoller JK. The Impact of Delayed Diagnosis of Alpha-1 Antitrypsin Deficiency: The Association Between Diagnostic Delay and Worsened Clinical Status. Respir Care. 2019;64(8):915-922. doi:10.4187/respcare.06555

19. Choi DT, Davila JA, Sansgiry S, et al. Factors Associated With Delay of Diagnosis of Hepatocellular Carcinoma in Patients With Cirrhosis [published online ahead of print, 2020 Jul 18]. Clin Gastroenterol Hepatol. 2020;S1542-3565(20)30988-5. doi:10.1016/j.cgh.2020.07.026

20. Walker GJ, Lin S, Chanchlani N, et al. Quality improvement project identifies factors associated with delay in IBD diagnosis. Aliment Pharmacol Ther. 2020;52(3):471-480. doi:10.1111/apt.15885

21. Lee HY, Han DJ, Kim KJ, Kim TH, Oh YM, Rhee CK. Clinical characteristics and economic burden of tuberculous-destroyed lung in Korea: a National Health Insurance Service-National Sample Cohortbased study. J Thorac Dis. 2019;11(6):2324-2331. doi:10.21037/jtd.2019.06.14

22. Rhee CK, Chau NQ, Yunus F, Matsunaga K, Perng DW; on behalf the COPD Assembly of the APSR. Management of COPD in Asia: A position statement of the Asian Pacific Society of Respirology. Respirology. 2019;24(10):1018-1025. doi:10.1111/resp.13633

23. Yang T, Cai B, Cao B, et al. REALizing and improving management of stable COPD in China: a multicenter, prospective, observational study to realize the current situation of COPD patients in China (REAL) - rationale, study design, and protocol. BMC Pulm Med. 2020;20(1):11. Published 2020 Jan 13. doi:10.1186/s12890-019-1000-x 
24. Cai L, Wang XM, Fan LM, Shen JR, Liu YN, Golden AR. Socioeconomic variations in chronic obstructive pulmonary disease prevalence, diagnosis, and treatment in rural Southwest China. $B M C$ Public Health. 2020;20(1):536. Published 2020 Apr 19. doi:10.1186/s12889-020-08687-5

25. Ramírez-Venegas $A$, Velázquez-Uncal M, Pérez-Hernández $R$, et al. Prevalence of COPD and respiratory symptoms associated with biomass smoke exposure in a suburban area. Int J Chron Obstruct Pulmon Dis. 2018;13:1727-1734. Published 2018 May 25. doi:10.2147/COPD.S156409

26. Estévez-García JA, Schilmann A, Riojas-Rodríguez H, et al. Women exposure to household air pollution after an improved cookstove program in rural San Luis Potosi, Mexico. Sci Total Environ. 2020;702:134456. doi:10.1016/j.scitotenv.2019.134456

27. Dziankowska-Zaborszczyk E, Bryla M, Ciabiada-Bryla B, Maniecka-Bryla I. Standard expected years of life lost (SEYLL) due to chronic obstructive pulmonary disease (COPD) in Poland from 1999 to 2014. PLoS One. 2019;14(3):e0213581. Published 2019 Mar 12. doi:10.1371/journal.pone. 0213581

28. McLaren S. The Relationship between living alone, sense of belonging, and depressive symptoms among older men: the moderating role of sexual orientation. Aging Ment Health. 2020;24(1):103-109. doi:10.1080/13607863.2018.1531373

29. Paino Pardal L, Poblet I Montells L, Ríos Álvarez L. Mayores que viven solos y malnutrición. Estudio SOLGER [The elderly living alone and malnutrition. SOLGER Study]. Aten Primaria. 2017;49(8):450458. doi:10.1016/j.aprim.2016.10.007

30. Local Burden of Disease Educational Attainment Collaborators. Mapping disparities in education across low- and middle-income countries. Nature. 2020;577(7789):235-238. doi:10.1038/s41586019-1872-1

31. Yusuf $S$, Joseph $P$, Rangarajan $S$, et al. Modifiable risk factors, cardiovascular disease, and mortality in 155722 individuals from 21 high-income, middle-income, and low-income countries (PURE): a prospective cohort study [published correction appears in Lancet. 2020 Mar 7;395(10226):784]. Lancet. 2020;395(10226):795-808. doi:10.1016/S0140-6736(19)32008-2

32. Gibson M, Hearty W, Craig P. The public health effects of interventions similar to basic income: a scoping review. Lancet Public Health. 2020;5(3):e165-e176. doi:10.1016/S2468-2667(20)30005-0

33. Mathisen J, Jensen AKG, Andersen I, Andersen GS, Hvidtfeldt UA, Rod NH. Education and incident type 2 diabetes: quantifying the impact of differential exposure and susceptibility to being overweight or obese. Diabetologia. 2020;63(9):1764-1774. doi:10.1007/s00125-020-05150-3

34. Wu YT, Daskalopoulou C, Muniz Terrera G, et al. Education and wealth inequalities in healthy ageing in eight harmonised cohorts in the ATHLOS consortium: a population-based study. Lancet Public Health. 2020;5(7):e386-e394. doi:10.1016/S2468-2667(20)30077-3

\section{Tables}

Table 1 Descriptive statistics of the outpatients' demographic characteristics. 


\begin{tabular}{|c|c|}
\hline Characteristics & $n=408$ \\
\hline \multicolumn{2}{|l|}{ First diagnosis, n (\%) } \\
\hline Yes & $137(33.6 \%)$ \\
\hline No & $271(66.4 \%)$ \\
\hline \multicolumn{2}{|l|}{ Sex, n (\%) } \\
\hline Male & $368(90.2 \%)$ \\
\hline Female & $40(9.8 \%)$ \\
\hline Age (years) ${ }^{*}$ & $65(58-69)$ \\
\hline \multicolumn{2}{|l|}{ Number of exacerbations in the previous year, $\mathrm{n}(\%)$} \\
\hline 0 & $169(41.5 \%)$ \\
\hline 1 & $111(27.3 \%)$ \\
\hline$\geq 2$ & $127(31.2 \%)$ \\
\hline Number of hospitalizations in the previous year ${ }^{*}$ & $0(0-1)$ \\
\hline Smoking pack-years ${ }^{*}$ & $40(20-58)$ \\
\hline FEV1\% predicted ${ }^{*}$ & $53.3(35.2-69.2)$ \\
\hline FEV1/FVC* & $47(36.4-58.9)$ \\
\hline CAT score* & $13(8-18)$ \\
\hline mMRC scale* & $2(1-3)$ \\
\hline COPD-Q* & $4(0-6)$ \\
\hline \multicolumn{2}{|l|}{ Residence, n (\%) } \\
\hline City & $135(33.1 \%)$ \\
\hline Rural area & $273(66.9 \%)$ \\
\hline \multicolumn{2}{|l|}{ Resident manner, $\mathrm{n}(\%)$} \\
\hline Live alone & $32(7.8 \%)$ \\
\hline Not living alone & $376(92.2 \%)$ \\
\hline Years of education* & $9(6-9)$ \\
\hline Average annual family income (ten thousand RMB)* & $1(0.5-2)$ \\
\hline \multicolumn{2}{|l|}{ Medical insurance, n (\%) } \\
\hline Yes & $399(97.8 \%)$ \\
\hline
\end{tabular}




\begin{tabular}{|l|l|}
\hline No & $9(2.2 \%)$ \\
\hline Hospiagnosis delay (days)* & $230(50-720)$ \\
First-level hospifical (I) & \\
Secondary hospital (II) & $67(16.4 \%)$ \\
Tertiary hospital (III) & $122(29.9 \%)$ \\
Receiving pulmonary function test in the first visit, $\mathrm{n}(\%)$ & $219(53.7 \%)$ \\
Yes & $193(47.3 \%)$ \\
No & $215(52.7 \%)$ \\
\hline
\end{tabular}

Notes: *non-normal distribution data and data were shown as median (interquartile range [IQR]).

Abbreviation: FEV1 - forced expiratory volume in one second; FVC: forced vital capacity; CAT, COPD Assessment Test; mMRC, modified Medical British Research Council; COPD-Q, Chronic Obstructive Pulmonary Disease Knowledge Questionnaire; IQR, interquartile range.

Table 2 Proportion of patients receiving pulmonary function test in the first visit, in different levels of hospitals

\begin{tabular}{|lllll|}
\hline $\begin{array}{l}\text { Proportion, } \mathbf{n} \\
(\%)\end{array}$ & $\begin{array}{l}\text { First-level hospital } \\
(\mathbf{I})\end{array}$ & $\begin{array}{l}\text { Secondary hospital } \\
(\mathrm{II})\end{array}$ & $\begin{array}{l}\text { Tertiary hospital (III) } \\
\mathbf{n}=\mathbf{6 7}\end{array}$ & $\mathbf{p}$ - value \\
\hline Yes & $1(1.5 \%)$ & $30(15.5 \%)$ & 1622 & \\
\hline No & $66(98.5 \%)$ & $92(75.4 \%)$ & $135(26.0 \%)$ & $<0.0001$ \\
\hline
\end{tabular}

Table 3 Wilcoxon test for characteristics differences in diagnosis delay. 


\begin{tabular}{|c|c|c|c|}
\hline \multirow[t]{4}{*}{ Diagnosis Delay ${ }^{\star}$} & \multicolumn{2}{|l|}{ Characteristics } & \multirow[t]{2}{*}{$p$-value } \\
\hline & Sex & & \\
\hline & Male & $210(44-720)$ & 0.209 \\
\hline & Female & $430(91-975)$ & \\
\hline \multicolumn{4}{|c|}{ Residence } \\
\hline & Rural area & $300(90-900)$ & $<0.001$ \\
\hline & City & $100(18-390)$ & \\
\hline & \multicolumn{3}{|l|}{ Resident manner } \\
\hline & Live alone & $660(255-2530)$ & $<0.001$ \\
\hline & Not living alone & $200(40-680)$ & \\
\hline & \multicolumn{3}{|l|}{ First diagnosis } \\
\hline & Yes & $165(30-660)$ & 0.052 \\
\hline & No & $270(67-855)$ & \\
\hline \multicolumn{4}{|c|}{ CAT } \\
\hline & $<10$ & $119(30-345)$ & $<0.001$ \\
\hline & $\geq 10$ & $300(90-1080)$ & \\
\hline \multicolumn{4}{|c|}{ mMRC } \\
\hline & $<2$ & $95(28-300)$ & $<0.001$ \\
\hline & $\geq 2$ & $300(90-1040)$ & \\
\hline \multicolumn{4}{|c|}{ Receiving PFT in the first visit } \\
\hline \multicolumn{4}{|c|}{ Yes } \\
\hline & \multirow[t]{2}{*}{ No } & $60(5-300)$ & 0.204 \\
\hline & & $39(3-200)$ & \\
\hline
\end{tabular}

Notes: *non-normal distribution data and data were shown as median (interquartile range [IQR]).

Abbreviation: CAT, COPD Assessment Test; mMRC, modified Medical British Research Council; PFT, Pulmonary function test.

Table 4 Kruskal-Wallis $\mathrm{H}$ analysis for characteristics differences of diagnosis delay. 


\begin{tabular}{|c|c|c|c|}
\hline \multirow[t]{6}{*}{ Diagnosis Delay^ } & \multicolumn{2}{|l|}{ Characteristics } & \multirow[t]{2}{*}{ p-value } \\
\hline & Age & & \\
\hline & $<50$ years & $10(5-29)$ & $<0.001$ \\
\hline & $50-60$ years & $50(5-200)$ & \\
\hline & $60-70$ years & $39(3-210)$ & \\
\hline & $\geq 70$ years & $100(3-300)$ & \\
\hline \multicolumn{4}{|c|}{ FEV1\% predicted } \\
\hline & $<30 \%$ & $535(175-2520)$ & $<0.001$ \\
\hline & $30-50 \%$ & $330(120-1410)$ & \\
\hline & $50-80 \%$ & $140(30-558)$ & \\
\hline & $\geq 80 \%$ & $60(15-300)$ & \\
\hline \multicolumn{4}{|c|}{$\mathrm{AE}$ in the previous year } \\
\hline & 0 & $210(48-660)$ & 0.358 \\
\hline & 1 & $210(36-615)$ & \\
\hline & $\geq 2$ & $270(62-1080)$ & \\
\hline \multicolumn{4}{|c|}{ Years of education } \\
\hline & $\leq 6$ years & $360(120-1380)$ & $<0.001$ \\
\hline & $7-\leq 9$ years & $210(30-579)$ & \\
\hline & $>9$ years & $99(14-300)$ & \\
\hline \multicolumn{4}{|c|}{ Average annual family income } \\
\hline & $<0.5$ Ten thousand RMB & $710(300-2300)$ & $<0.001$ \\
\hline & $0.5-1$ Ten thousand RMB & $240(90-720)$ & \\
\hline & 1 - 2 Ten thousand RMB & $210(60-594)$ & \\
\hline & $\geq 2$ Ten thousand RMB & $45(12-255)$ & \\
\hline
\end{tabular}


Notes: *non-normal distribution data and data were shown as median (interquartile range [IQR]).

\section{Figures}

\section{0 outpatients admitted with}

\section{COPD}

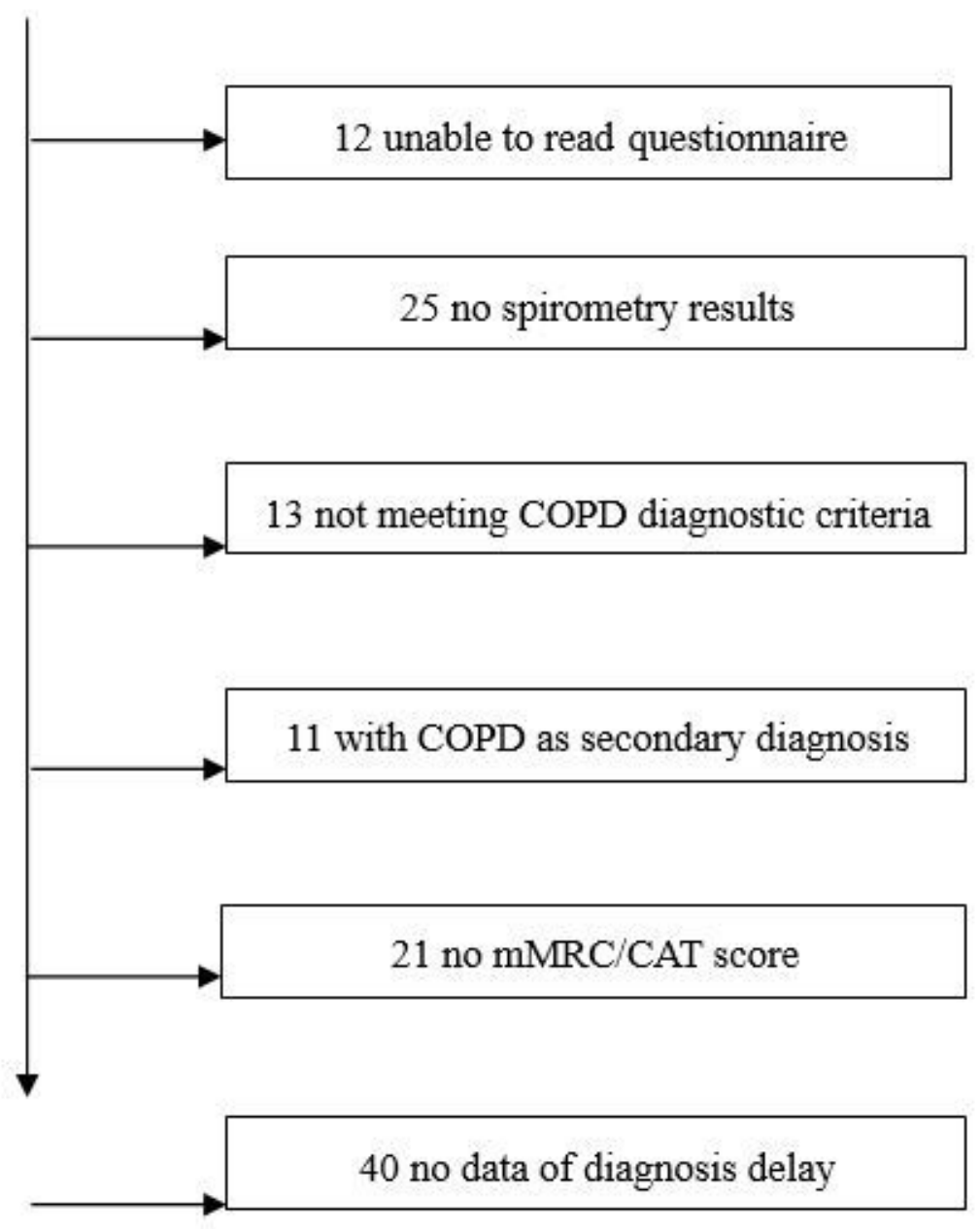

408 outpatients met study

criteria (2019/7-2020/2)

Figure 1 
Study flow chart. Abbreviation: COPD, chronic obstructive pulmonary disease; mMRC, modified Medical British Research Council dyspnea scale; CAT, COPD assessment test.

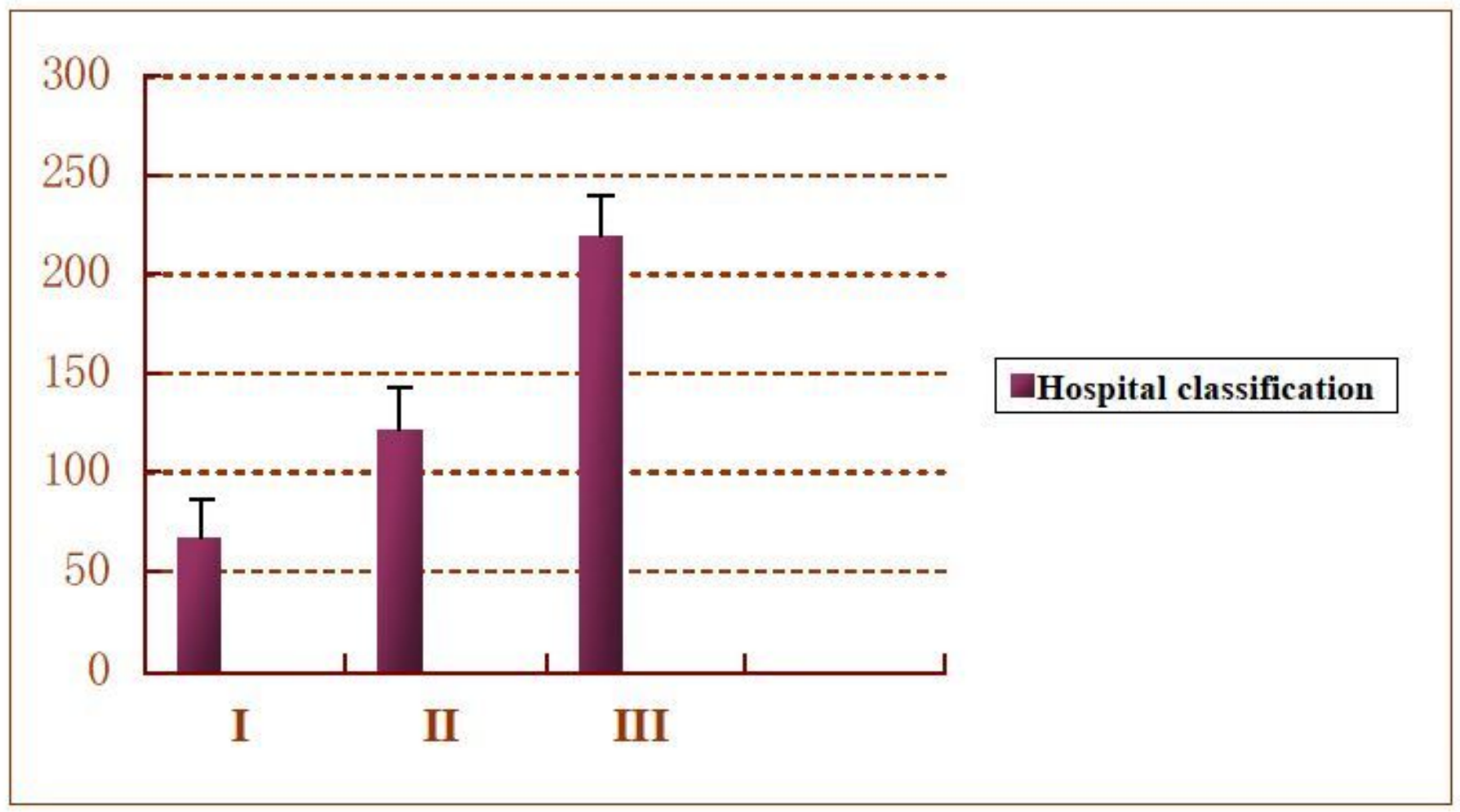

Figure 2

Distribution of medical institutions with the first diagnosis of COPD patients. Abbreviation: I, First-level hospital; II, Secondary hospital; III, Tertiary hospital. 


\section{Relationship}

$t(136)=-4.22, p=<0.001, \hat{r}_{\text {Pearson }}=-0.34, \mathrm{Cl}_{95 \%}[-0.48,-0.18], n_{\text {pairs }}=138$

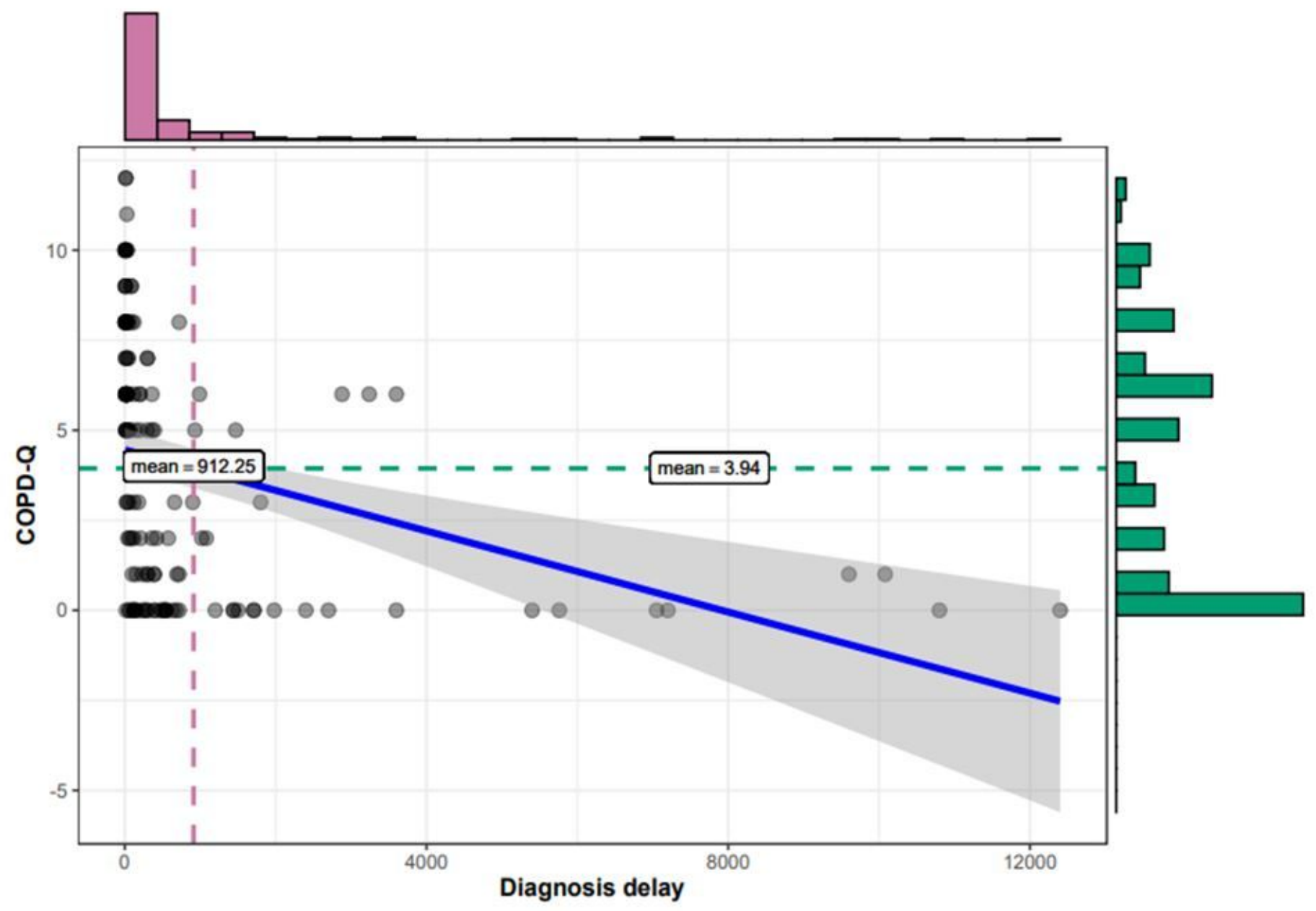

$\log _{e}\left(\mathrm{BF}_{01}\right)=-6.16, \hat{\rho}_{\text {median }}=-0.33, \mathrm{Cl}_{95 \%}^{\mathrm{HDI}}[-0.48,-0.20], r_{\text {Cauchy }}^{\mathrm{JZS}}=0.71$

\section{Figure 3}

Correlation analysis between COPD-Q and diagnosis delay. Abbreviation: COPD-Q, Chronic Obstructive Pulmonary Disease Knowledge Questionnaire. 


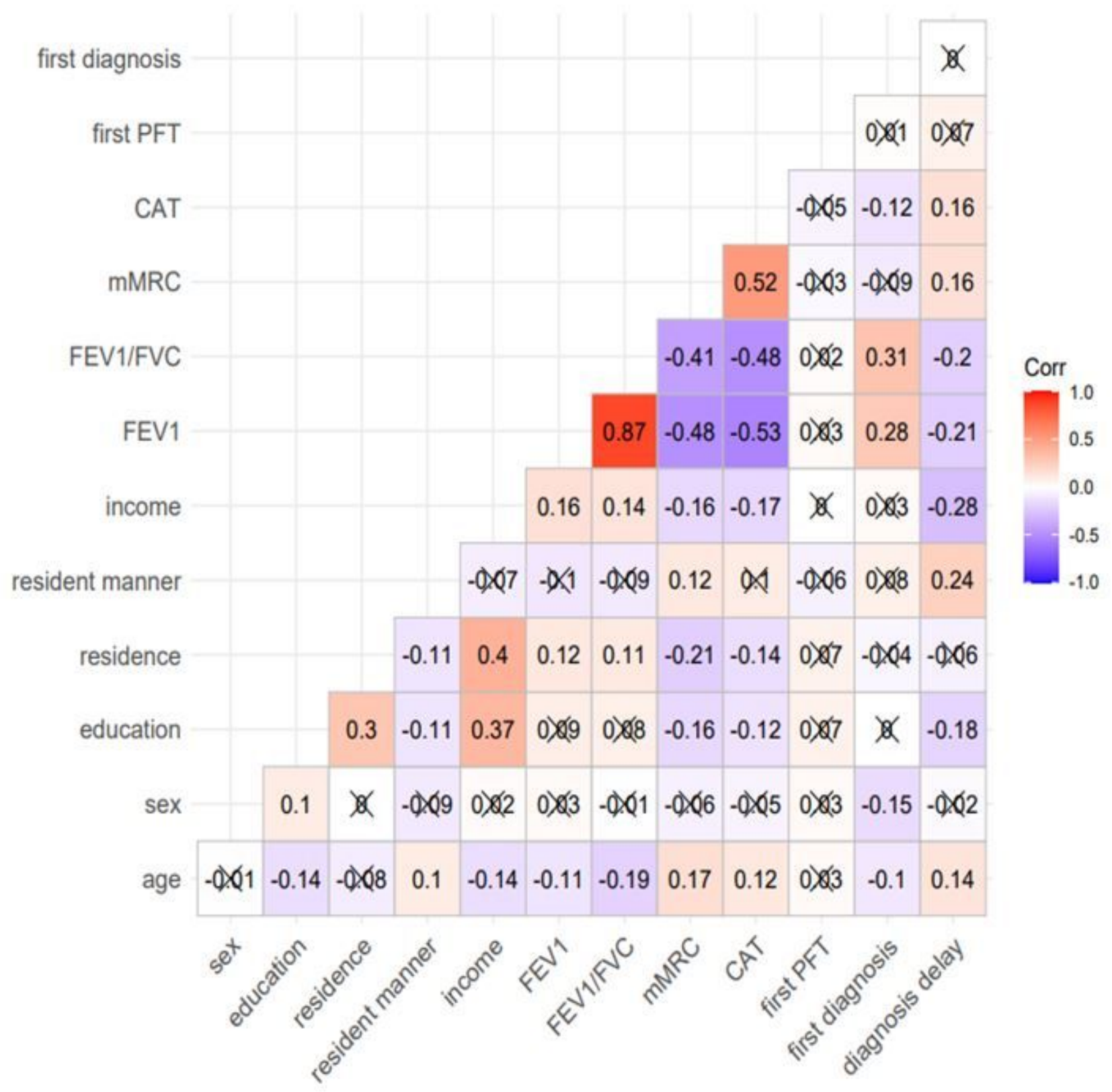

Figure 4

Correlation analysis between characteristics differences and diagnosis delay. 